\title{
Novel $\mathrm{BaTiO}_{3}$-Based, Ag/Pd-Compatible Lead-Free Relaxors with Superior Energy Storage Performance
}

\author{
Huijing Yang, Zhilun Lu, Linhao Li, Weichao Bao, Hongfen Ji, Jinglei Li, Antonio Feteira, \\ Fangfang $\mathrm{Xu}$, Yong Zhang, Huajun Sun, Zhichao Huang, Weichao Lou, Kaixin Song, Shikuan Sun, \\ Ge Wang,* Dawei Wang,* and Ian M. Reaney
}

Cite This: ACS Appl. Mater. Interfaces 2020, 12, 43942-43949

Read Online

\section{ACCESS | Lill Metrics \& More | 回 Article Recommendations | sl Supporting Information}

ABSTRACT: Ceramic dielectrics are reported with superior energy storage performance for applications, such as power electronics in electrical vehicles. A recoverable energy density $\left(W_{\text {rec }}\right)$ of $\sim 4.55 \mathrm{~J} \mathrm{~cm}^{-3}$ with $\eta \sim 90 \%$ is achieved in lead-free relaxor $\mathrm{BaTiO}_{3}$ $0.06 \mathrm{Bi}_{2 / 3}\left(\mathrm{Mg}_{1 / 3} \mathrm{Nb}_{2 / 3}\right) \mathrm{O}_{3}$ ceramics at $\sim 520 \mathrm{kV} \mathrm{cm}{ }^{-1}$. These ceramics may be co-fired with $\mathrm{Ag} / \mathrm{Pd}$, which constitutes a major step forward toward their potential use in the fabrication of commercial multilayer ceramic capacitors. Compared to stoichiometric $\mathrm{Bi}\left(\mathrm{Mg}_{2 / 3} \mathrm{Nb}_{1 / 3}\right)$ $\mathrm{O}_{3}$-doped $\mathrm{BaTiO}_{3}(\mathrm{BT})$, A-site deficient $\mathrm{Bi}_{2 / 3}\left(\mathrm{Mg}_{1 / 3} \mathrm{Nb}_{2 / 3}\right) \mathrm{O}_{3}$ reduces the electrical heterogeneity of BT. Bulk conductivity differs from the grain boundary only by 1 order of magnitude which, coupled with a smaller volume fraction of conducting cores due to enhanced diffusion of the dopant via A-site vacancies in the A-site sublattice, results in higher breakdown strength under an electric field. This strategy can be employed to develop new dielectrics with improved energy storage performance.

KEYWORDS: energy storage, capacitors, lead-free, $\mathrm{BaTiO}_{3}$, dielectric, ceramics

\section{INTRODUCTION}

Energy storage technologies such as lithium-ion batteries and electrolytic super-capacitors have been the focus of much recent research. ${ }^{1,2}$ Batteries provide long-lasting energy/power through a continuous slow discharge rate whereas supercapacitors charge and discharge more rapidly and are primarily used in kinetic energy recovery systems. ${ }^{3-10}$ However, their polymeric components mean that they have limited temperature stability. ${ }^{11}$ In contrast, ceramic dielectric capacitors do not offer such high energy density but are stable above $100{ }^{\circ} \mathrm{C}$ and are finding applications in high temperature, high power electronics in electric vehicles, and in pulsed power and laser applications. $^{12-15}$

The total energy density

$$
W_{\text {total }}=\int E d P
$$

recoverable energy density

$$
W_{\text {rec }}=\int_{P_{r}}^{P_{\max }} E d P
$$

and energy conversion efficiency

$$
\eta=\frac{W_{\text {rec }}}{W_{\text {total }}}
$$

for nonlinear dielectric capacitors are obtained from the integration of polarization-electric field ( $\mathrm{P}-\mathrm{E})$ loop, where $P_{\max }$ is maximum polarization and $\mathrm{P}_{\mathrm{r}}$ is remanent polarization. Therefore, both large $\Delta P\left(P_{\max }-P_{\mathrm{r}}\right)$ and maximum applied electric field $\left(E_{\max }\right)$ are desirable for achieving high $W_{\text {rec }}$ and $\eta$.
The $W_{\text {rec }}$ and $\eta$ for ferroelectrics (FEs) are restricted because of low $\Delta P$ and $E_{\max }$. Instead, weakly nonlinear relaxor-FEs (RFEs) and anti-FEs (AFEs) are generally proposed as potential candidates for high energy density ceramic capacitors, with compositions commonly based on $\mathrm{BaTiO}_{3}(\mathrm{BT}),{ }^{16-25}$ $\mathrm{Na}_{0.5} \mathrm{Bi}_{0.5} \mathrm{TiO}_{3}(\mathrm{NBT}),{ }^{26-29} \mathrm{BiFeO}_{3}(\mathrm{BF}),{ }^{30-37} \mathrm{NaN}-$ $\mathrm{bO}_{3}(\mathrm{NN}),{ }^{38-40} \mathrm{~K}_{0.5} \mathrm{Na}_{0.5} \mathrm{NbO}_{3}(\mathrm{KNN}),{ }^{41-44}$ and $\mathrm{AgNbO}_{3}$ (AN) ceramics. ${ }^{13,45,46}$ Even though excellent $E_{\max }(>400 \mathrm{kV}$ $\left.\mathrm{cm}^{-1}\right)$ and $\eta(>80 \%)$ have been achieved in RFE ceramics, $W_{\text {rec }}$ is still limited by low $P_{\max }\left(<45 \mu \mathrm{C} \mathrm{cm}{ }^{-2}\right)$ which requires further improvement to achieve $W_{\text {rec }}>4 \mathrm{~J} \mathrm{~cm}^{-3}$. AFEs possess larger $P_{\max }$ at an intermediate electric field $\left(\sim 300 \mathrm{kV} \mathrm{cm}^{-1}\right)$ but saturation of the polarization restricts $W_{\text {rec }}$ and they often exhibit low $\eta(<70 \%)$ because of the field induced transition to the FE state.

BT-based ceramics are commercially the most attractive candidates for high energy density storage since they are already utilized for consumer electronics at low fields as filters and de-couplers. The first example of improved $W_{\text {rec }}(2.3 \mathrm{~J}$ $\mathrm{cm}^{-3}$ at $225 \mathrm{kV} \mathrm{cm}^{-1}$ ) for BT-based compositions was $0.7 \mathrm{BT}$ $0.3 \mathrm{BiScO}_{3}$ (0.7BT-0.3BS) bulk ceramics, whose properties

Received: July 22, 2020

Accepted: September 4, 2020

Published: September 4, 2020 
(a)
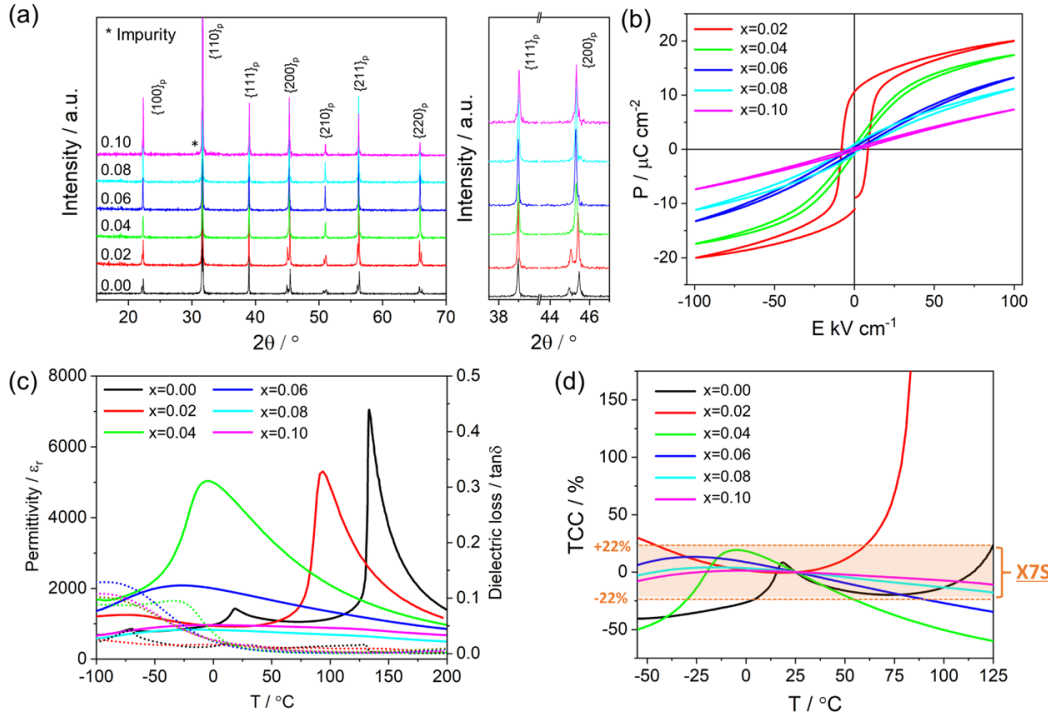

Figure 1. (a) X-ray powder diffraction patterns in a $2 \theta$ range from 15 to $70^{\circ}$ with representative $\{111\}_{\mathrm{p}}$ and $\{200\}_{\mathrm{p}} \mathrm{XRD}$ reflections for $x \mathrm{~B}_{2 / 3} \mathrm{MN}$ BT. (b) Bipolar P-E loops and (c) temperature-dependent $\varepsilon_{\mathrm{r}}$ (Solid line) and $\tan \delta$ (Dashed line) data for $x \mathrm{~B}_{2 / 3} \mathrm{MN}$-BT ceramics with $x=0.00-$ 0.10. (d) TCC value for $x \mathrm{~B}_{2 / 3} \mathrm{MN}-\mathrm{BT}$ ceramics with $\mathrm{x}=0.00-0.10$ in a temperature range from -55 to $125^{\circ} \mathrm{C}$.

were enhanced to $6.1 \mathrm{~J} \mathrm{~cm}^{-3}$ in multilayer ceramic capacitors (MLCCs). ${ }^{25}$ The same research group reported 0.7BT-0.3BS MLCCs which exhibited much better temperature stability ( $<15 \%$ from 0 to $300{ }^{\circ} \mathrm{C}$ ) and $W_{\text {rec }}$ compared with commercial X7R (poor temperature stabilities) and COG (low $W_{\text {rec }}$ and $\left.E_{\max }\right)$ capacitors.

Stoichiometric $\mathrm{Bi}\left(\mathrm{Mg}_{2 / 3} \mathrm{Nb}_{1 / 3}\right) \mathrm{O}_{3}$ (BMN) is a commonly reported third end-member or dopant in perovskite solid solutions and has been shown to optimize $W_{\text {rec }}$ by promoting a weakly nonlinear relaxor state. ${ }^{25,47,48}$ Solid solutions which incorporate a range of ion sizes and valences on the $\mathrm{A}$ and $\mathrm{B}$ sites of the perovskite structure disrupt coupling between polarisable species $\left(\mathrm{Bi}^{3+}, \mathrm{Ti}^{4+}\right.$ and $\left.\mathrm{Nb}^{5+}\right)$, reducing $P_{\mathrm{r}}$ but simultaneously creating an "active solid solution" of local disordered regions within a pseudocubic matrix, which can be addressed by an electric field leading to high $P_{\max }{ }^{49}$

This strategy has been adopted in many lead-free systems to effectively enhance $\Delta P$ and $W_{\text {rec }}$ for example, $0.10 \mathrm{BMN}-\mathrm{BT}$ $\left(1.18 \mathrm{~J} \mathrm{~cm}^{-3}\right),{ }^{50} 0.06$ BMN-BF-BT $\left(1.56 \mathrm{~J} \mathrm{~cm}^{-3}\right),{ }^{51} 0.15$ BMN-NN $\left.\left(2.8 \mathrm{~J} \mathrm{~cm}^{-3}\right)\right)^{38}$ and 0.10 BMN-KNN (4.08 J $\left.\mathrm{cm}^{-3}\right) .{ }^{41}$ Such dopant strategies are often accompanied by an increase in electrical homogeneity and reduction of grain size/ porosity, leading to enhanced $E_{\max } \cdot 3,36,43,52$ However, the role of A-site vacancies $\left(V_{\mathrm{A}}\right)$ is rarely addressed in "active solid solutions".

In this study, a solid solution of BT with A-site deficient $\mathrm{Bi}_{2 / 3}\left(\mathrm{Mg}_{1 / 3} \mathrm{Nb}_{2 / 3}\right) \mathrm{O}_{3}\left(\mathrm{~B}_{2 / 3} \mathrm{MN}\right)$ has been synthesized and the role of $V_{\mathrm{A}}$ in optimizing $E_{\max }$ and $W_{\text {rec }}$ is investigated. Small concentrations of $V_{\mathrm{A}}$ have been reported previously to improve the conductivity of lead-free dielectrics, such as $\mathrm{SrTiO}_{3}$ (ST) and $\mathrm{BT} .{ }^{53-55}$ In addition, we postulate that $V_{\mathrm{A}}$ reduces the concentration of Bi based alloying addition required to induce a weakly nonlinear relaxor state, thereby enhancing compatibility with conventional $\mathrm{Ag}-\mathrm{Pd}$ electrodes which react with $\mathrm{Bi}$ at high temperatures.

We demonstrate that $\mathrm{A}$-site deficient $x \mathrm{~B}_{2 / 3} \mathrm{MN}-\mathrm{BT}$ exhibits a bulk and grain boundary response similar to conventional BMN-BT ceramics but the total conductivity is at least one order of magnitude lower. The lower conductivity leads to an enhancement of $E_{\max } \sim 520 \mathrm{kV} \mathrm{cm}^{-1}\left(\sim 270 \mathrm{kV} \mathrm{cm}^{-1}\right.$ for
BMN-BT) and results in $W_{\text {rec }} \sim 4.55 \mathrm{~J} \mathrm{~cm}^{-3}$ and $\eta \sim 92 \%$ in compositions with $x=0.06$. Although several materials have similar $W_{\text {rec }}{ }^{17-19}$ A-site deficient $\mathrm{xB}_{2 / 3} \mathrm{MN}-\mathrm{BT}$ compositions were also shown to be compatible with $\mathrm{Ag}-\mathrm{Pd}$ metal, suggesting potential for commercialization as high-voltage, high-temperature MLCCs.

\section{EXPERIMENTAL PROCEDURES}

A-site deficient $x \mathrm{Bi}_{2 / 3}\left(\mathrm{Mg}_{1 / 3} \mathrm{Nb}_{2 / 3}\right) \mathrm{O}_{3}-(1-x) \mathrm{BaTiO}_{3}\left(x \mathrm{~B}_{2 / 3} \mathrm{MN}\right.$ BT) ceramics, with $(x=0.00,0.02,0.04,0.06,0.08$, and 0.10$)$ solid solution were synthesized using a conventional solid-state reaction with analytical-grade raw powders of $\mathrm{BaCO}_{3}(>99.5 \%), \mathrm{TiO}_{2}$ (>99.9\%), $\mathrm{MgO}(>99.9 \%), \mathrm{Nb}_{2} \mathrm{O}_{5}(>99.5 \%)$, and $\mathrm{Bi}_{2} \mathrm{O}_{3}(>99.9 \%)$. Excess $0.5 \mathrm{~mol} \% \mathrm{Bi}_{2} \mathrm{O}_{3}$ was added to compensate for Bi-loss during processing and $\mathrm{Li}_{2} \mathrm{CO}_{3}$ was used as a fluxing agent to reduce the sintering temperature. ${ }^{56-58}$ Mixed powders were ball milled for $16 \mathrm{~h}$, dried, and calcined $2 \mathrm{~h}$ at $900{ }^{\circ} \mathrm{C}$. After calcination, the mixed powder was ball milled for $16 \mathrm{~h}$, dried, and uniaxially pressed into $10 \mathrm{~mm}$ diameter pellets, followed by sintering $4 \mathrm{~h}$ from $1050-1200{ }^{\circ} \mathrm{C}$. The density of sintered ceramic pellets was evaluated using the Archimedes principle, yielding relative densities $>95 \%$ of theoretical. To investigate the chemical compatibility of A-site deficient $x \mathrm{~B}_{2 / 3} \mathrm{MN}$ BT with the $\mathrm{Ag}-\mathrm{Pd}(70-30 \%)$ electrode, 20 wt \% of $\mathrm{Ag}-\mathrm{Pd}$ electrode ink was mixed with ceramic powders and co-fired $4 \mathrm{~h}$ in air at $1100{ }^{\circ} \mathrm{C}$

X-ray diffraction (XRD) was performed using a D2 phaser X-ray diffractometer on crushed pellets, annealing for $5 \mathrm{~h}$ in air at $550{ }^{\circ} \mathrm{C}$ to eliminate residual stress. Specimens for scanning electron microscopy (SEM) were ground, polished, thermally etched at $1080{ }^{\circ} \mathrm{C}$ for 30 min, and carbon coated. Thermally etched ceramics were evaluated using an FEI Inspect F50 SEM, equipped with backscattered electron (BSE) and energy-dispersive X-ray spectroscopy (EDX) detectors. Samples for transmission electron microscopy (TEM) were ground manually to $\sim 50 \mu \mathrm{m}$, followed by polishing to electron transparency using an Argon ion mill (PIPS II 695, Gatan, USA). Samples were examined with a JEOL JEM 2100F (JEOL, Tokyo, Japan) operated at $200 \mathrm{kV}$.

Ceramic pellets for electrical measurements were ground to 0.2 $\mathrm{mm}$, gold sputter-coated for $1 \mathrm{~min}$. FE P-E measurements were performed using an aixACCT TF2000E system with a $1 \mathrm{~Hz}$ triangular signal. Temperature-dependent permittivity and loss were examined using an Agilent 4184A precision LCR meter from -100 to $200{ }^{\circ} \mathrm{C}$ from $1 \mathrm{kHz}$ to $1 \mathrm{MHz}$. The electrical microstructure was evaluated 


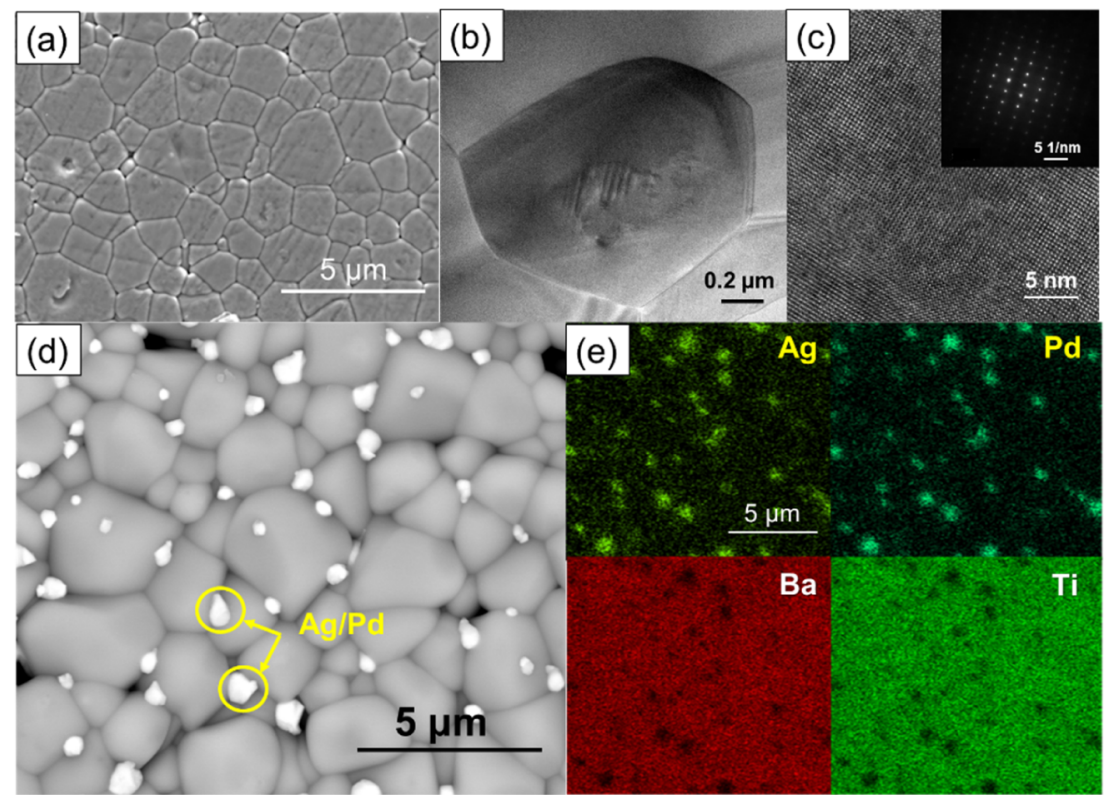

Figure 2. (a) Thermal-etched SEM surface image for $0.06 \mathrm{~B}_{2 / 3} \mathrm{MN}-\mathrm{BT}$ ceramic. (b) Bright-field TEM image of grains in $0.06 \mathrm{~B}_{2 / 3} \mathrm{MN}-\mathrm{BT}$ ceramics. (c) High-resolution TEM images with $\langle 110\rangle$ diffraction patterns. (d) BSE surface micrographs of $\mathrm{Ag}-\mathrm{Pd}$ co-fired $0.06 \mathrm{~B}_{2 / 3} \mathrm{MN}-\mathrm{BT}$ ceramics. (e) EDX mapping distribution of $\mathrm{Ag}, \mathrm{Pd}, \mathrm{Ba}$, and $\mathrm{Ti}$ elements.

using an Agilent E4980A impedance AC analyzer from room temperature (RT) to $800{ }^{\circ} \mathrm{C}$ at $25{ }^{\circ} \mathrm{C}$ intervals on heating. Impedance data $\left(Z^{\prime \prime}\right.$ and $\left.M^{\prime \prime}\right)$ were normalized by a geometric factor (thickness/surface area) and fitted using ZView software (Scribner Associates, Inc., Southern Pines, NC), as reported previously. ${ }^{59-61}$

\section{RESULTS AND DISCUSSION}

\subsection{Crystal Structure, Dielectric, and FE Properties.} The crystal structure of ceramic powders was examined using XRD data collected in $15-70^{\circ} 2 \theta$ range, as shown Figure 1a. A single-phase perovskite is observed for compositions with $x \leq$ 0.06. A secondary phase (peaks labelled in Figure 1a) is presented in $x=0.08$ and $x=0.10$, indicating that the solubility limit of $\mathrm{B}_{2 / 3} \mathrm{MN}$ in $\mathrm{BT}$ has been reached. Doublets merge into single peaks as $x$ increases, suggesting a transformation from tetragonal into pseudocubic symmetry, in which the correlation length of polar order decreases. Fullpattern refinement of the diffraction data for all single-phase compositions was carried out, Table S1 (Supporting Information), confirming a pseudocubic phase for $x>0.02$, Figure S1 (Supporting Information).

Bipolar P-E loops obtained at $100 \mathrm{kV} \mathrm{cm}{ }^{-1}$ for $x \mathrm{~B}_{2 / 3} \mathrm{MN}$ BT ceramics are displayed in Figures $1 \mathrm{~b}$ and S2 (P-E loop for $\mathrm{BT}$ at $60 \mathrm{kV} \mathrm{cm}^{-1}$, Supporting Information). A FE P-E loop is observed for $x=0.00$ and 0.02 , with $P_{\max } \sim 20 \mu \mathrm{C} \mathrm{cm}^{-2}$ and $P_{\mathrm{r}}$ $\sim 12 \mu \mathrm{C} \mathrm{cm}^{-2}$. Both $P_{\max }$ and $P_{\mathrm{r}}$ reduce gradually but $\Delta P$ increases with $x$, indicating a FE to RFE transition. The temperature-dependent relative permittivity $\left(\varepsilon_{\mathrm{r}}\right.$, solid line $)$ and dielectric loss ( $\tan \delta$, dashed line) at $100 \mathrm{kHz}$ for $x \mathrm{~B}_{2 / 3} \mathrm{MN}-\mathrm{BT}$ ceramics are shown in Figure 1c. The sharp anomalies for BT at $\sim 135{ }^{\circ} \mathrm{C}\left(\varepsilon_{\mathrm{r}} \sim 7000\right), 22{ }^{\circ} \mathrm{C}\left(\varepsilon_{\mathrm{r}} \sim 1750\right)$, and $-70{ }^{\circ} \mathrm{C}\left(\varepsilon_{\mathrm{r}} \sim\right.$ 950) correspond to the cubic-tetragonal, tetragonal-orthorhombic, and orthorhombic-rhombohedral phase transitions, respectively. ${ }^{62}$ As $x$ increases, the maximum $\varepsilon_{\mathrm{r}}$ decreases continuously reaching 1000 for $x=0.10$, which shows a rather temperature independent $\varepsilon_{\mathrm{r}}$. Temperature-independent permittivity were reported for conventional BMN-BT solid solution by Reaney and co-workers with temperature coefficient of capacitance $\left(\right.$ TCC) $< \pm 15 \%{ }^{63}$ Here, TCC values for $x \mathrm{~B}_{2 / 3} \mathrm{MN}-\mathrm{BT}(x \geq 0.04)$ at $100 \mathrm{~Hz}$ were calculated, as shown Figure $1 \mathrm{~d}$, with $x=0.08$ and $x=0.10$ exhibiting TCC $< \pm 22 \%$ from -55 to $125{ }^{\circ} \mathrm{C}$, corresponding to an X7S specification. Frequency-dependent dielectric properties for $x \mathrm{~B}_{2 / 3} \mathrm{MN}-\mathrm{BT}$ ceramics are shown in Figure S3 (Supporting Information). A frequency-independent dielectric peak occurs at $\sim 135$ and $102{ }^{\circ} \mathrm{C}$ for $x=0.00$ and $x=0.02$, respectively, corresponding to the Curie temperature $\left(T_{\mathrm{c}}\right)$ but a frequency dispersion is observed in $\varepsilon_{\mathrm{r}}-T$ curve for $x>0.02$, indicating relaxor behavior.

3.2. Microstructure. SEM images of thermal-etched surfaces for $x \mathrm{~B}_{2 / 3} \mathrm{MN}-\mathrm{BT}$ ceramics are shown in Figure $2 \mathrm{a}(x$ $=0.06$ ) and Figure S4 (Supporting Information). The average grain size reduces with increasing $x$ from $25 \mu \mathrm{m}$ for $x=0.00$ to $\sim 2.8 \mu \mathrm{m}$ for $x=0.06$, Table S2 (Supporting Information). Secondary phases are observed for $x=0.08$ and $x=0.10$ at the grain boundary. TEM images of a ceramic with $x=0.06$, as shown in Figure 2b,c, revealed some cores with FE or tweedlike domains surrounded by a largely featureless pseudocubic shell (Figure 2b).

Most research into BT-based MLCCs with superior $W_{\text {rec }}$ utilize Pt as inner electrodes; however, the use of such expensive noble metal precludes their commercial exploitation in mass production applications. ${ }^{17-19,24,64}$ It is therefore, essential to evaluate compatibility of potential MLCCs dielectric layers against lower cost electrode systems such as $\mathrm{Ni}, \mathrm{Ag}$, or $\mathrm{Ag}-\mathrm{Pd}$. In the case of Bi-based or containing compounds, reaction with $\mathrm{Ni}$ is a well-known phenomenon, which is often accompanied by decomposition at the low $\mathrm{p}\left(\mathrm{O}_{2}\right)$ required for co-firing with $\mathrm{Ni}$ internal electrodes. ${ }^{65,66}$ The sintering of Bi-based compounds with pure Ag electrodes is also problematic and limited to co-firing at $<8500^{\circ} \mathrm{C}$ because of melting of Ag. Even for systems which can co-fire at $<850$ ${ }^{\circ} \mathrm{C}$, the reaction of $\mathrm{Bi}$ containing compounds with $\mathrm{Ag}$ is common depending on the thermodynamic stability of the $\mathrm{Bi}$ compound in the presence of Ag. This is exemplified by $\mathrm{Bi}_{2} \mathrm{Mo}_{2} \mathrm{O}_{9}$ which reacts with $\mathrm{Ag}$ electrodes to form $\mathrm{Ag}$ - 

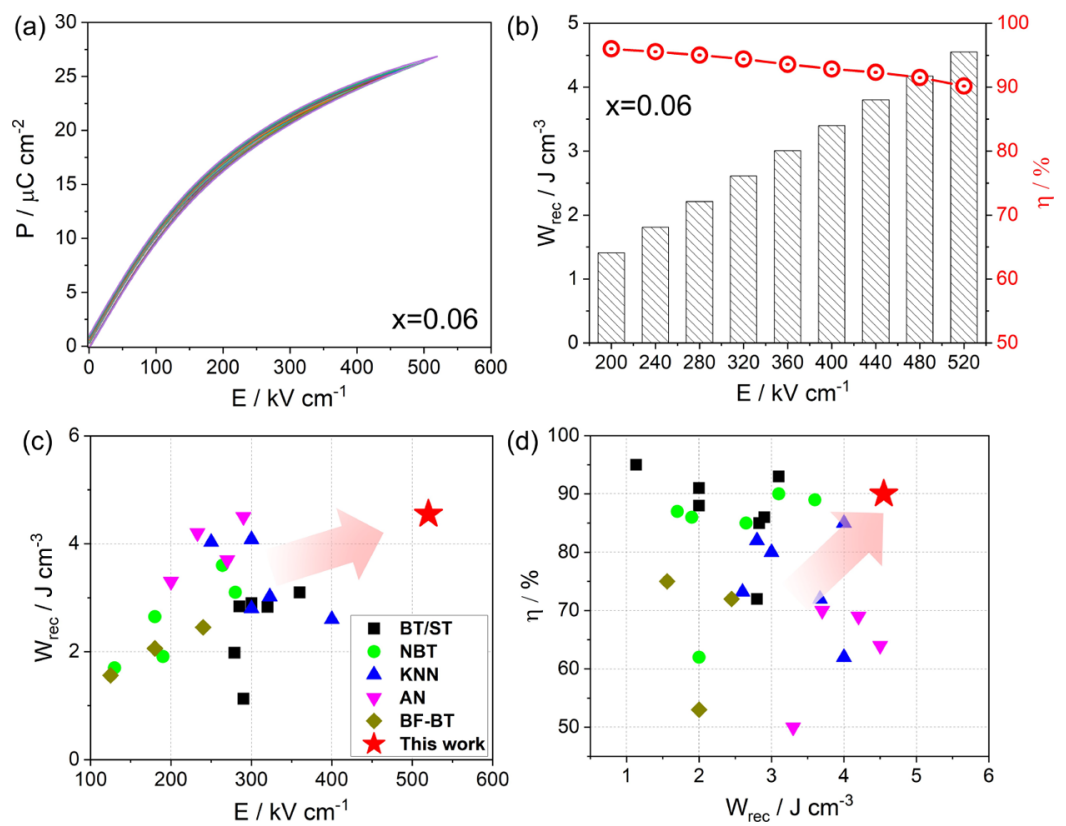

Figure 3. (a) Unipolar P-E loops under $E_{\max }$ and (b) calculated $W_{\text {rec }}$ and $\eta$ at different electric field for $0.06 \mathrm{~B}_{2 / 3} \mathrm{MN}-\mathrm{BT}$ ceramics. (c) Comparisons of electric field vs $W_{\text {rec }}$ and (d) $W_{\text {rec }}$ vs $\eta$ among lead-free dielectric ceramics, including BT-based, ${ }^{24,25,50}$ NBT-based, ${ }^{26,27,29} \mathrm{KNN}$ based, ${ }^{38,41,43,44}$ AN-based, ${ }^{13}$ and BF-based. ${ }^{30,31,36,51} *$ The author only used data points from the references to compare with our reported data and there is no any graphics that are reproduced from any other resource.
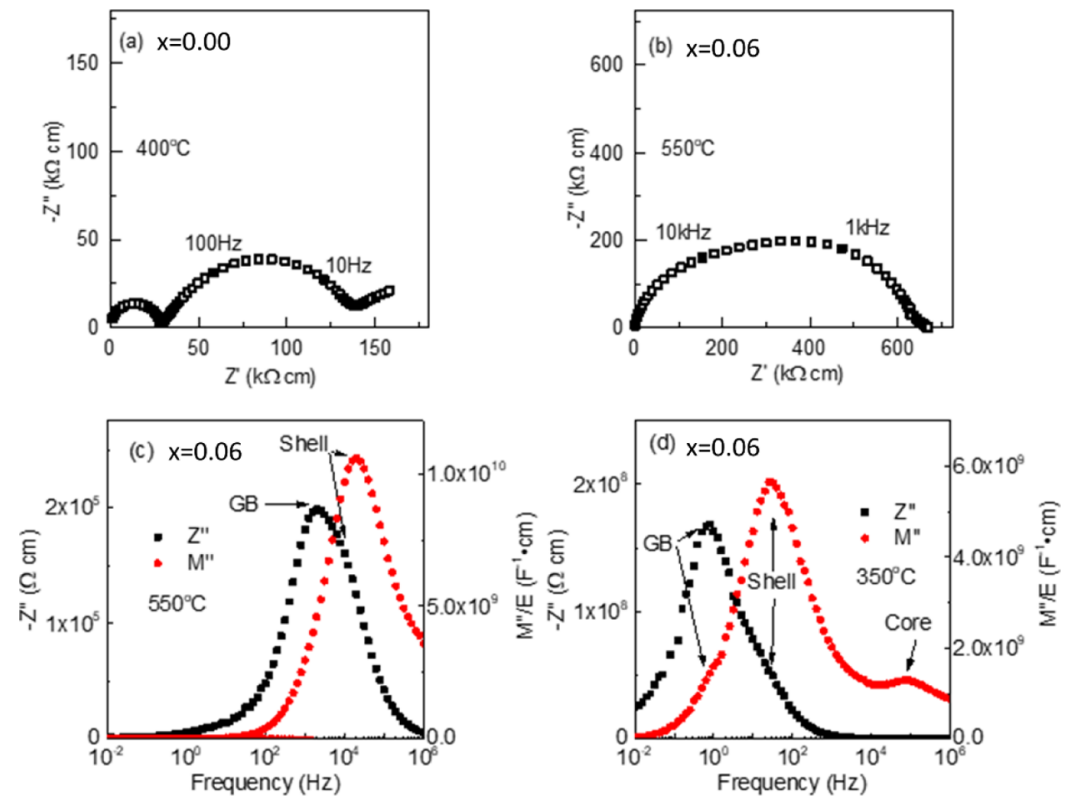

Figure 4. $Z^{*}$ plots of $x \mathrm{~B}_{2 / 3} \mathrm{MN}-\mathrm{BT}$ ceramics with (a) $x=0.00$ at $400{ }^{\circ} \mathrm{C}$ and (b) $x=0.06$ at $550{ }^{\circ} \mathrm{C}$. Spectroscopic plots of $Z^{\prime \prime}$ and $M^{\prime \prime}$ for $x=0.06$ at (c) 550 and (d) $350{ }^{\circ} \mathrm{C}$.

molybdate compounds. ${ }^{67}$ The sintering temperature of compositions with $x=0.06$ is $>850{ }^{\circ} \mathrm{C}$, and therefore, the use of pure $\mathrm{Ag}$ can be ruled out but alternatively $\mathrm{Ag}-\mathrm{Pd}$ alloys can be employed at higher temperatures.

In this study, we have therefore investigated the compatibility of $0.06 \mathrm{~B}_{2 / 3} \mathrm{MN}-\mathrm{BT}$ with $\mathrm{Ag}-\mathrm{Pd}$. SEM images and EDX mapping do not reveal chemical interaction between $\mathrm{Ag}-\mathrm{Pd}$ particles and ceramic grains, as shown in Figure 2d,e, indicating that $0.06 \mathrm{~B}_{2 / 3} \mathrm{MN}-\mathrm{BT}$ is a promising material for the commercial fabrication of MLCCs.

3.3. Energy Storage Performance. The energy storage properties are obtained from unipolar $\mathrm{P}-\mathrm{E}$ loops under the
$E_{\max }$. The low $\Delta P$ and $E_{\max }\left(<200 \mathrm{kV} \mathrm{cm}^{-1}\right)$ of BT gave a poor response, as predicted, and the energy storage properties are not illustrated in this contribution. The unipolar $\mathrm{P}-\mathrm{E}$ loops of $x \mathrm{~B}_{2 / 3} \mathrm{MN}-\mathrm{BT}(0.02 \leq x \leq 0.08)$ at $E_{\max }$ are shown in Figure $\mathrm{S} 5 \mathrm{a}-\mathrm{d}$ (Supporting Information), with corresponding $E_{\max }$ and $\Delta P$ displayed in Figure S6a (Supporting Information). The highest $E_{\max } \sim 520 \mathrm{kV} \mathrm{cm}^{-1}$ and $\Delta P \sim 25 \mu \mathrm{C} \mathrm{cm}^{-2}$ are both obtained for ceramics with $x=0.06$, as shown Figure $3 \mathrm{a}$. The $W_{\text {rec }}$ and $\eta$ for compositions with $0.02 \leq x \leq 0.08$ are calculated and displayed in Figure $\mathrm{S} 5 \mathrm{e}-\mathrm{h}$ (Supporting Information). The highest $W_{\text {rec }} \sim 4.55 \mathrm{~J} \mathrm{~cm}^{-3}$ and $\eta \sim 90 \%$ are obtained for $0.06 \mathrm{~B}_{2 / 3} \mathrm{MN}-\mathrm{BT}$ at $E_{\max } \sim 520 \mathrm{kV} \mathrm{cm}{ }^{-1}$ 

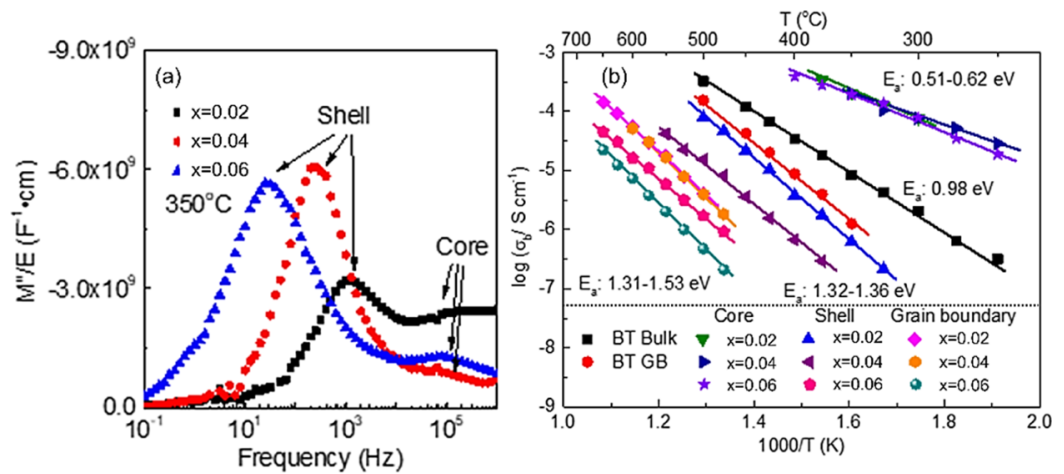

Figure 5. (a) Spectroscopic plots of $M^{\prime \prime}$ for $x \mathrm{~B}_{2 / 3} \mathrm{MN}-\mathrm{BT}$ ceramics $(0.02 \leq x \leq 0.06)$ at $350{ }^{\circ} \mathrm{C}$. (b) Arrhenius plot of conductivity of different components in $x \mathrm{~B}_{2 / 3} \mathrm{MN}-\mathrm{BT}(0.00 \leq x \leq 0.06)$.

(Figures $3 \mathrm{~b}$ and $\mathrm{S} 6 \mathrm{~b}$, Supporting Information), exhibiting the highest $W_{\text {rec }}$ values compared to all reported BT-based leadfree ceramics to date (Figure 3c,d). Other systems have recently shown higher $W_{\text {rec }}$ but this is accompanied by either poor efficiency $(<70 \%)$ such as AN or cannot be co-fired with internal electrodes other than $\mathrm{Pt}$, for example $\mathrm{BF}^{36}$ compounds.

3.4. Electrical Microstructure. Complex impedance plane plots and spectroscopic plots of $Z^{\prime \prime}$ and $M^{\prime \prime}$ data for $x \mathrm{~B}_{2 / 3} \mathrm{MN}$ BT ceramics are given in Figure 4 for various temperatures. BT consisted of three components at $400{ }^{\circ} \mathrm{C}$ : two semicircles and a low-frequency spike, as shown in Figure 4a. These data were interpreted based on an equivalent circuit comprising three parallel resistor-capacitor elements connected in series. ${ }^{59-61}$ The capacitance extracted from these three components from high to low frequency are $30 \mathrm{pF}, 20 \mathrm{nF}$, and $5 \mu \mathrm{F}$ and are attributed to grain (bulk), grain boundary, and electrode responses, respectively. Contrary to $\mathrm{BT}$, only one arc is observed in all $x \mathrm{~B}_{2 / 3} \mathrm{MN}-\mathrm{BT}$ samples, for example, $x=0.06$ at $550{ }^{\circ} \mathrm{C}$, as shown in Figure $4 \mathrm{~b}$. However, the inspection of the combined $Z^{\prime \prime}$ and $M^{\prime \prime}$ spectroscopic plots at $550{ }^{\circ} \mathrm{C}$ indicate this arc should consist of two semicircles representing two electroactive regions with similar resistivity, as shown in Figure 4c. The capacitances for high- and low-frequency arcs are 50 and $250 \mathrm{pF}$ which correspond to grain and grain boundary contributions, respectively. In addition, one more $M^{\prime \prime}$ peak is observed at lower temperatures $\left(350{ }^{\circ} \mathrm{C}\right)$, as shown in Figure $4 \mathrm{~d}$. It has a corresponding capacitance of $200 \mathrm{pF}$ which suggests it is also a bulk response. Therefore, $x \mathrm{~B}_{2 / 3} \mathrm{MN}-\mathrm{BT}$ ceramics exhibit an electrical core-shell microstructure, in agreement with TEM images, as shown in Figure $2 \mathrm{~b}$. The change in capacitance $\left(C=1 / 2 M^{\prime \prime}\right)$ indicates a decreasing core and increasing shell volume fraction with increasing $x$, as shown in Figure 5a. Assuming the permittivity for the core and shell remains relatively similar for all $x \mathrm{~B}_{2 / 3} \mathrm{MN}$-BT ceramics, the volume fraction of the core/shell region decreases from $40 / 60$ to $20 / 80$ for $x=0.02$ and $x=0.06$, respectively. Similar bulk and grain boundary responses were also reported in conventional, $y \mathrm{BMN}-\mathrm{BT}(y=0.05-0.20)$ ceramics but total resistivity obtained from $Z^{*}$-plot for $x \mathrm{~B}_{2 / 3} \mathrm{MN}-\mathrm{BT}$ is at least one order of magnitude larger, which explains the enhancement of $E_{\max }{ }^{50}$

The conductivity of different components in $x \mathrm{~B}_{2 / 3} \mathrm{MN}-\mathrm{BT}$ are summarized in an Arrhenius plot, as shown in Figure 5b. The conductivity of the core, $\sigma_{\mathrm{b}, \text { core }}$ of all three samples $(x=$ $0.02,0.04$, and 0.06$)$ are similar. However, with increasing $x$, the conductivity of the shell, $\sigma_{\mathrm{b}, \text { shell }}$, and grain boundary, $\sigma_{\mathrm{gb}}$, decreases by 2 and 1 order of magnitude, respectively. The activation energy, $E_{a}$, of both core and shell remains relatively unchanged at $\sim 0.51-0.62 \mathrm{eV}$ for $\sigma_{\mathrm{b}, \text { core }}$ and $1.32-1.36 \mathrm{eV}$ for $\sigma_{\mathrm{b}, \text { shell }} . \sigma_{\mathrm{b}}$ and $\sigma_{\mathrm{gb}}$ of BT is lower than the $\sigma_{\mathrm{b}, \text { core }}$ of $\mathrm{xB}_{2 / 3} \mathrm{MN}-\mathrm{BT}$ ceramics but higher than the $\sigma_{\mathrm{b}, \text { shell }}$ with an $E_{\mathrm{a}}$ of 0.98 and 1.35 $\mathrm{eV}$, respectively.

For BT $(x=0.00), \sigma_{\mathrm{gb}}$ is lower than $\sigma_{\mathrm{b}}$, especially around RT because of the higher activation energy of $\sigma_{\mathrm{gb}}$ compared to $\sigma_{\mathrm{b}}$. Under an electrical field, therefore, the voltage applied at the grain boundary is higher than the bulk which leads to a much higher local field. The enhancement of $E_{\max }$ in $x \mathrm{~B}_{2 / 3} \mathrm{MN}$ BT (especially for $x=0.06$ ) is attributed to the following three facts: (i) the total conductivity, $\sigma_{\text {total }}$, decreases with increasing $x$ doping level. The $\sigma_{\text {total }}$ of composition with $x=0.06$ is $\sim 3$ orders and $>1$ order of magnitude lower than BT and BMNBT ceramics, respectively, which leads to a reduction in leakage current under at a high field. (ii) The conductivity difference between bulk $\left(\sigma_{\mathrm{b}, \text { shell }}\right.$ in $\left.x=0.06\right)$ and grain boundary response is higher in $x=0.00$ than $x=0.06$. The difference in $E_{\mathrm{a}}$ is 0.32 and $0.22 \mathrm{eV}$ compositions with $x=0.00$ and $x=0.06$, respectively, which also means that the difference in $\sigma_{\mathrm{b} \text {,shell }}$ and $\sigma_{\mathrm{gb}}$ at RT is significantly smaller in $0.06 \mathrm{~B}_{2 / 3} \mathrm{MN}-\mathrm{BT}$ than BT. Despite the existence of some core-shell grains, the shell region constitutes $\sim 80 \%$ of the volume fraction of $0.06 \mathrm{~B}_{2 / 3} \mathrm{MN}-\mathrm{BT}$ and cannot be bypassed by the current. Thus, the voltage is more evenly distributed throughout the sample in $0.06 \mathrm{~B}_{2 / 3} \mathrm{MN}-\mathrm{BT}$ compare to $\mathrm{BT}$ which leads to a high $E_{\max }$. (iii) the much smaller grain size of $0.06 \mathrm{~B}_{2 / 3} \mathrm{MN}-\mathrm{BT}$ $(\sim 2.8 \mu \mathrm{m})$ compared with BT $(\sim 25 \mu \mathrm{m})$ and BMN-BT $(\sim 6-$ $10 \mu \mathrm{m})$ ceramics yields a higher volume fraction of the grain boundary and consequently reduces local electrical fields. We postulate that the lower volume fraction of cores in $\mathrm{xB}_{2 / 3} \mathrm{MN}$ $\mathrm{BT}$ is attributed to the greater diffusion rates of dopants through cubo-octahedral interstices in comparison with BMNBT.

\section{CONCLUSIONS}

In summary, A-site deficient $x \mathrm{Bi}_{2 / 3}\left(\mathrm{Mg}_{1 / 3} \mathrm{Nb}_{2 / 3}\right) \mathrm{O}_{3}$ - $\mathrm{BT}$ $\left(x \mathrm{~B}_{2 / 3} \mathrm{MN}-\mathrm{BT}\right.$ with $\left.x=0.00-0.10\right)$ ceramics were successfully fabricated using the solid-state reaction. A phase transition from $\mathrm{FE}$ to RFE, associated with structural transformation from tetragonal to cubic, is observed in $x \mathrm{~B}_{2 / 3} \mathrm{MN}-\mathrm{BT}$ ceramics with increasing $x$. A record high $E_{\max } \sim 520 \mathrm{kV} \mathrm{cm}^{-1}$ and $W_{\text {rec }}$ $\sim 4.55 \mathrm{~J} \mathrm{~cm}^{-3}$ for BT-based compositions were realized in ceramics with $x=0.06$ which may be co-fired with $\mathrm{Ag}-\mathrm{Pd}$ without a chemical reaction. Impedance data revealed that the high $E_{\max }$ for $0.06 \mathrm{~B}_{2 / 3} \mathrm{MN}-\mathrm{BT}$ ceramics was because of a 
reduction in the total electrical conductivity, with greater electrical homogeneity between different electrical components and an overall smaller volume fraction of cores. Compared to $\mathrm{BMN}-\mathrm{BT}$, the presence of $V_{\mathrm{A}}$ in $\mathrm{xB}_{2 / 3} \mathrm{MN}-\mathrm{BT}$ not only encouraged electrical homogeneity but also reduces the concentration of $\mathrm{Bi}$ on the $\mathrm{A}$-site ensuring greater compatibility with $\mathrm{Ag}-\mathrm{Pd}$ electrodes.

\section{ASSOCIATED CONTENT}

\section{SI Supporting Information}

The Supporting Information is available free of charge at https://pubs.acs.org/doi/10.1021/acsami.0c13057.

Full-pattern refinement of $x \mathrm{~B}_{2 / 3} \mathrm{MN}-\mathrm{BT}$ ceramics with refined crystallography details; $\mathrm{P}-\mathrm{E}$ loop for $\mathrm{BT}$ ceramics; frequency-dependent dielectric properties for $x \mathrm{~B}_{2 / 3} \mathrm{MN}-\mathrm{BT}(x=0.00 \leq x \leq 0.10)$ ceramics; SEM image of thermal-etched surfaces for $x \mathrm{~B}_{2 / 3} \mathrm{MN}-\mathrm{BT}(x=$ $0.00 \leq x \leq 0.10)$ ceramics with average grain size information; and unipolar P-E loops under $E_{\max }$ and $(\mathrm{e}-\mathrm{h})$ calculated energy storage properties $\left(W_{\text {rec }} \eta, E_{\max }\right.$ and $\Delta P$ ) at different electric fields for $x \mathrm{~B}_{2 / 3} \mathrm{MN}-\mathrm{BT}$ ceramics (PDF)

\section{AUTHOR INFORMATION}

\section{Corresponding Authors}

Ge Wang - Department of Materials Science and Engineering, University of Sheffield, Sheffield S1 3JD, U.K.; (1) orcid.org/ 0000-0003-1842-8067; Email: g.wang@sheffield.ac.uk

Dawei Wang - Department of Materials Science and Engineering, University of Sheffield, Sheffield S1 3JD, U.K.; Email: dawei.wang@sheffield.ac.uk

\section{Authors}

Huijing Yang - Department of Materials Science and Engineering, University of Sheffield, Sheffield S1 3JD, U.K.; Department of Physics, Tangshan Normal University, Tangshan 063000, China

Zhilun Lu - Department of Materials Science and Engineering, University of Sheffield, Sheffield S1 3JD, U.K.; The Henry Royce Institute, Sheffield S1 3JD, U.K.

Linhao Li - Department of Materials Science and Engineering, University of Sheffield, Sheffield S1 3JD, U.K.

Weichao Bao - State Key Laboratory of High Performance Ceramics and Superfine Microstructure, Shanghai Institute of Ceramics, Shanghai 200050, China

Hongfen Ji - Department of Materials Science and Engineering, University of Sheffield, Sheffield S1 3JD, U.K.; Laboratory of Thin Film Techniques and Optical Test, Xi'an Technological University, Xi'an 710032, China

Jinglei Li - Electronic Materials Research Laboratory, Key Laboratory of the Ministry of Education and International Center for Dielectric Research, Xi'an Jiaotong University, Xi'an 710049, China

Antonio Feteira - Materials and Engineering Research Institute, Sheffield Hallam University, Sheffield S1 1WB, U.K.

Fangfang Xu - State Key Laboratory of High Performance Ceramics and Superfine Microstructure, Shanghai Institute of Ceramics, Shanghai 200050, China; orcid.org/0000-00025570-4289

Yong Zhang - State Key Laboratory of Silicate Materials for Architectures, School of Materials Science and Engineering, Wuhan University of Technology, Wuhan 430070, China
Huajun Sun - State Key Laboratory of Silicate Materials for Architectures, School of Materials Science and Engineering, Wuhan University of Technology, Wuhan 430070, China; (1) orcid.org/0000-0003-1898-088X

Zhichao Huang - Materials and Engineering Research Institute, Sheffield Hallam University, Sheffield S1 1WB, U.K.; College of Electronics Information, Hangzhou Dianzi University, Hangzhou 310018, China

Weichao Lou - Materials and Engineering Research Institute, Sheffield Hallam University, Sheffield S1 1WB, U.K.; College of Electronics Information, Hangzhou Dianzi University, Hangzhou 310018, China

Kaixin Song - College of Electronics Information, Hangzhou Dianzi University, Hangzhou 310018, China; 이이.org/ 0000-0002-4622-1234

Shikuan Sun - Department of Materials Science and Engineering, University of Sheffield, Sheffield S1 3JD, U.K.; ○ orcid.org/0000-0002-1688-5072

Ian M. Reaney - Department of Materials Science and Engineering, University of Sheffield, Sheffield S1 3JD, U.K.; (1) orcid.org/0000-0003-3893-6544

Complete contact information is available at: https://pubs.acs.org/10.1021/acsami.0c13057

\section{Author Contributions}

H.Y., Z.L., L.L., and W.B. contributed equally to this work. Notes

The authors declare no competing financial interest.

\section{ACKNOWLEDGMENTS}

This work was supported by the Engineering and Physical Sciences Research Council (EP/L017563/1 and EP/ N010493/1), Henry Royce Institute for Advanced Materials, funded through EPSRC grants EP/R00661X/1, EP/S019367/ 1, EP/P02470X/1 and EP/P025285/1 and National Natural Science Foundation of China (51602060 and 51402005). The authors are grateful for support provided by Functional Materials and Devices group from The University of Sheffield.

\section{REFERENCES}

(1) Liu, C.; Li, F.; Ma, L.-P.; Cheng, H.-M. Advanced Materials for Energy Storage. Adv. Mater. 2010, 22, E28-E62.

(2) Chen, H.; Cong, T. N.; Yang, W.; Tan, C.; Li, Y.; Ding, Y. Progress in Electrical Energy Storage System: A critical review. Prog. Nat. Sci.: Mater. 2009, 19, 291-312.

(3) Yu, Z.; Jiao, S.; Li, S.; Chen, X.; Song, W.-L.; Teng, T.; Tu, J.; Chen, H.-S.; Zhang, G.; Fang, D.-N. Flexible Stable Solid-State Al-Ion Batteries. Adv. Funct. Mater. 2019, 29, 1806799.

(4) Wang, S.; Jiao, S.; Wang, J.; Chen, H.-S.; Tian, D.; Lei, H.; Fang, D.-N. High-Performance Aluminum-Ion Battery with CuS@C Microsphere Composite Cathode. ACS Nano 2017, 11, 469-477.

(5) Song, Y.; Jiao, S.; Tu, J.; Wang, J.; Liu, Y.; Jiao, H.; Mao, X.; Guo, Z.; Fray, D. J. A long-lifeRechargeable Al Ion Battery based on Molten Salts. J. Mater. Chem. A. 2017, 5, 1282-1291.

(6) Sun, H.; Wang, W.; Yu, Z.; Yuan, Y.; Wang, S.; Jiao, S. A new Aluminium-ion Battery with High Voltage, High Dafety and Low Cost. Chem. Commun. 2015, 51, 11892-11895.

(7) Wang, W.; Jiang, B.; Xiong, W.; Sun, H.; Lin, Z.; Hu, L.; Tu, J.; Hou, J.; Zhu, H.; Jiao, S. A new Cathode Material for Super-valent Battery based on Auminium IonIntercalation and Deintercalation. Sci. Rep. 2013, 3, 3383.

(8) Wang, S.; Yu, Z.; Tu, J.; Wang, J.; Tian, D.; Liu, Y.; Jiao, S. A Novel Aluminum-Ion Battery: $\mathrm{Al} / \mathrm{AlCl}_{3}$-[EMIm]Cl/Ni3S2@Graphene. Adv. Energy Mater. 2016, 6, 1600137. 
(9) Jiao, H.; Wang, C.; Tu, J.; Tian, D.; Jiao, S. A rechargeable Al-ion battery: $\mathrm{Al} /$ molten $\mathrm{AlCl}_{3}-$ urea/graphite. Chem. Commun. 2017, 53, 2331-2334.

(10) Zhang, X.; Jiao, S.; Tu, J.; Song, W.-L.; Xiao, X.; Li, S.; Wang, M.; Lei, H.; Tian, D.; Chen, H.; Fang, D. Rechargeable Ultrahighcapacity Tellurium-aluminum Batteries. Energy Environ. Sci. 2019, 12, 1918-1927.

(11) Chu, B.; Zhou, X.; Ren, K.; Neese, B.; Lin, M.; Wang, Q.; Bauer, F.; Zhang, Q. M. A Dielectric Polymer with High Electric Energy Density and Fast Discharge Speed. Science 2006, 313, 334336.

(12) Love, G. R. Energy Storage in Ceramic Dielectrics. J. Am. Ceram. Soc. 1990, 73, 323-328.

(13) Zhao, L.; Liu, Q.; Gao, J.; Zhang, S.; Li, J.-F. Lead-Free Antiferroelectric Silver Niobate Tantalate with High Energy Storage Performance. Adv. Mater. 2017, 29, 1701824.

(14) Yang, L.; Kong, X.; Li, F.; Hao, H.; Cheng, Z.; Liu, H.; Li, J.-F.; Zhang, S. Perovskite Lead-free Dielectrics for Energy Storage Applications. Prog. Mater. Sci. 2019, 102, 72-108.

(15) Sun, Z.; Wang, Z.; Tian, Y.; Wang, G.; Wang, W.; Yang, M.; Wang, X.; Zhang, F.; Pu, Y. Progress, Outlook, and Challenges in Lead-Free Energy-Storage Ferroelectrics. Adv. Electron. Mater. 2020, 6, 1900698.

(16) Shen, Z.; Wang, X.; Luo, B.; Li, L. $\mathrm{BaTiO}_{3}-\mathrm{BiYbO}_{3}$ Perovskite Materials for Energy Storage Applications. J. Mater. Chem. A. 2015, 3, 18146-18153.

(17) Cai, Z.; Zhu, C.; Wang, H.; Zhao, P.; Chen, L.; Li, L.; Wang, X. High-temperature Lead-free Multilayer Ceramic Capacitors with Ultrahigh Energy Density and Efficiency Fabricated via Two-step Sintering. J. Mater. Chem. A. 2019, 7, 14575-14582.

(18) Chen, L.; Wang, H.; Zhao, P.; Zhu, C.; Cai, Z.; Cen, Z.; Li, L.; Wang, X. Multifunctional $\mathrm{BaTiO}_{3}-\left(\mathrm{Bi}_{0.5} \mathrm{Na}_{0.5}\right) \mathrm{TiO}_{3}$-based MLCC with High-energy Storage Properties and Temperature Stability. J. Am. Ceram. Soc. 2019, 102, 4178-4187.

(19) Zhao, P.; Wang, H.; Wu, L.; Chen, L.; Cai, Z.; Li, L.; Wang, X. High-Performance Relaxor Ferroelectric Materials for Energy Storage Applications. Adv. Energy Mater. 2019, 9, 1803048.

(20) Li, W.-B.; Zhou, D.; Pang, L.-X. Enhanced Energy Storage Density by Inducing Defect Dipoles in Lead Free Relaxor Ferroelectric $\mathrm{BaTiO}_{3}$-based Ceramics. Appl. Phys. Lett. 2017, 110, 132902. (21) Li, W.-B.; Zhou, D.; Xu, R.; Wang, D.-W.; Su, J.-Z.; Pang, L.-X.; Liu, W.-F.; Chen, G.-H. $\mathrm{BaTiO}_{3}$-Based Multilayers with Outstanding Energy Storage Performance for High Temperature Capacitor Applications. ACS Appl. Energy Mater. 2019, 2, 5499-5506.

(22) Hu, Q.; Tian, Y.; Zhu, Q.; Bian, J.; Jin, L.; Du, H.; Alikin, D. O.; Shur, V. Y.; Feng, Y.; Xu, Z.; Wei, X. Achieve Ultrahigh Energy Storage Performance in $\mathrm{BaTiO}_{3}-\mathrm{Bi}\left(\mathrm{Mg}_{1 / 2} \mathrm{Ti}_{1 / 2}\right) \mathrm{O}_{3}$ Relaxor Ferroelectric Ceramics via Nano-scale Polarization Mismatch and Reconstruction. Nano Energy 2020, 67, 104264.

(23) Li, W.-B.; Zhou, D.; Pang, L.-X.; Xu, R.; Guo, H.-H. Novel Barium Titanate Based Capacitors with High Energy Density and Fast Discharge Performance. J. Mater. Chem. A. 2017, 5, 19607-19612.

(24) Li, W.-B.; Zhou, D.; Xu, R.; Pang, L.-X.; Reaney, I. M. $\mathrm{BaTiO}_{3}-$ $\operatorname{Bi}\left(\mathrm{Li}_{0.5} \mathrm{Ta}_{0.5}\right) \mathrm{O}_{3}$, Lead-Free Ceramics, and Multilayers with High Energy Storage Density and Efficiency. ACS Appl. Energy Mater. 2018, $1,5016-5023$.

(25) Ogihara, H.; Randall, C. A.; Trolier-McKinstry, S. High-Energy Density Capacitors Utilizing $0.7 \mathrm{BaTiO}_{3}-0.3 \mathrm{BiScO}_{3}$ Ceramics. J. Am. Ceram. Soc. 2009, 92, 1719-1724.

(26) Li, F.; Zhai, J.; Shen, B.; Liu, X.; Zeng, H. Simultaneously Highenergy Storage Density and Responsivity in Quasi-hysteresis-free Mndoped $\mathrm{Bi}_{0.5} \mathrm{Na}_{0.5} \mathrm{TiO}_{3}-\mathrm{BaTiO}_{3}-\left(\mathrm{Sr}_{0.7} \mathrm{Bi}_{0.2} \square_{0.1}\right) \mathrm{TiO}_{3}$ Ergodic Relaxor Ceramics. Mater. Res. Lett. 2018, 6, 345-352.

(27) Pan, Z.; Hu, D.; Zhang, Y.; Liu, J.; Shen, B.; Zhai, J. Achieving High Discharge Energy Density and Efficiency with NBT-based Ceramics for Application in Capacitors. J. Mater. Chem. C 2019, 7, 4072-4078.

(28) Wu, J.; Mahajan, A.; Riekehr, L.; Zhang, H.; Yang, B.; Meng, N.; Zhang, Z.; Yan, H. Perovskite $\operatorname{Srx}\left(\mathrm{Bi}_{1-\mathrm{x}} \mathrm{Na}_{0.97-\mathrm{x}} \mathrm{Li}_{0.03}\right)_{0.5} \mathrm{TiO}_{3}$
Ceramics with Polar Nano Regions for High Power Energy Storage. Nano Energy 2018, 50, 723-732.

(29) Li, J.; Li, F.; Xu, Z.; Zhang, S. Multilayer Lead-Free Ceramic Capacitors with Ultrahigh Energy Density and Efficiency. Adv. Mater. 2018, 30, 1802155.

(30) Wang, D.; Fan, Z.; Li, W.; Zhou, D.; Feteira, A.; Wang, G.; Murakami, S.; Sun, S.; Zhao, Q.; Tan, X.; Reaney, I. M. High Energy Storage Density and Large Strain in $\mathrm{Bi}\left(\mathrm{Zn}_{2 / 3} \mathrm{Nb}_{1 / 3}\right) \mathrm{O}_{3}$-Doped $\mathrm{BiFeO}_{3}-\mathrm{BaTiO}_{3}$ Ceramics. ACS Appl. Energy Mater. 2018, 1, 4403-4412.

(31) Wang, D.; Fan, Z.; Zhou, D.; Khesro, A.; Murakami, S.; Feteira, A.; Zhao, Q.; Tan, X.; Reaney, I. M. Bismuth Ferrite-based Lead-free Ceramics and Multilayers with High Recoverable Energy Density. J. Mater. Chem. A. 2018, 6, 4133-4144.

(32) Wang, D.; Wang, G.; Murakami, S.; Fan, Z.; Feteira, A.; Zhou, D.; Sun, S.; Zhao, Q.; Reaney, I. M. $\mathrm{BiFeO}_{3}-\mathrm{BaTiO}_{3}$ : A New Generation of Lead-free Electroceramics. J. Adv. Dielectr. 2018, 08, 1830004.

(33) Wang, G.; Li, J.; Zhang, X.; Fan, Z.; Yang, F.; Feteira, A.; Zhou, D.; Sinclair, D. C.; Ma, T.; Tan, X.; Wang, D.; Reaney, I. M. Ultrahigh Energy Storage Density Lead-free Multilayers by Controlled Electrical Homogeneity. Energy Environ. Sci. 2019, 12, 582-588.

(34) Qi, H.; Xie, A.; Tian, A.; Zuo, R. Superior Energy-Storage Capacitors with Simultaneously Giant Energy Density and Efficiency Using Nanodomain Engineered $\mathrm{BiFeO}_{3}-\mathrm{BaTiO}_{3}-\mathrm{NaNbO}_{3}$ Lead-Free Bulk Ferroelectrics. Adv. Energy Mater. 2020, 10, 1903338.

(35) Wang, G.; Lu, Z.; Li, J.; Ji, H.; Yang, H.; Li, L.; Sun, S.; Feteira, A.; Yang, H.; Zuo, R.; Wang, D.; Reaney, I. M. Lead-free (Ba,Sr) $\mathrm{TiO}_{3}$ - $\mathrm{BiFeO}_{3}$ Nased Multilayer Veramic Vapacitors with High Energy Density. J. Eur. Ceram. Soc. 2020, 40, 1779-1783.

(36) Wang, G.; Lu, Z.; Yang, H.; Ji, H.; Mostaed, A.; Li, L.; Wei, Y.; Feteira, A.; Sun, S.; Sinclair, D. C.; Wang, D.; Reaney, I. M. Fatigue Resistant Lead-free Multilayer Ceramic Capacitors with Ultrahigh Energy Density. J. Mater. Chem. A. 2020, 8, 11414-11423.

(37) Lu, Z.; Wang, G.; Bao, W.; Li, J.; Li, L.; Mostaed, A.; Yang, H.; Ji, H.; Li, D.; Feteira, A.; Xu, F.; Sinclair, D. C.; Wang, D.; Liu, S.-Y.; Reaney, I. M. Superior Energy Density through Tailored Dopant Strategies in Multilayer Ceramic Capacitors. Energy Environ. Sci. 2020, DOI: 10.1039/D0EE02104K.

(38) Ye, J.; Wang, G.; Zhou, M.; Liu, N.; Chen, X.; Li, S.; Cao, F.; Dong, X. Excellent Comprehensive Energy Storage Properties of Novel Lead-free $\mathrm{NaNbO}_{3}$-based Ceramics for Dielectric Capacitor Applications. J. Mater. Chem. C 2019, 7, 5639-5645.

(39) Zhou, M.; Liang, R.; Zhou, Z.; Dong, X. Superior Energy Storage Properties and Excellent Stability of Novel NaNbO3-based Lead-free Ceramics with A-site Vacancy obtained via a $\mathrm{Bi}_{2} \mathrm{O}_{3}$ Substitution Strategy. J. Mater. Chem. A. 2018, 6, 17896-17904.

(40) Qi, H.; Zuo, R.; Xie, A.; Tian, A.; Fu, J.; Zhang, Y.; Zhang, S. Ultrahigh Energy-Storage Density in $\mathrm{NaNbO}_{3}$-Based Lead-Free Relaxor Antiferroelectric Ceramics with Nanoscale Domains. Adv. Funct. Mater. 2019, 29, 1903877.

(41) Shao, T.; Du, H.; Ma, H.; Qu, S.; Wang, J.; Wang, J.; Wei, X.; $\mathrm{Xu}, \mathrm{Z}$. Potassium-sodium Niobate based Lead-free ceramics: Novel Electrical Energy Storage Materials. J. Mater. Chem. A. 2017, 5, 554563.

(42) Qu, B.; Du, H.; Yang, Z.; Liu, Q. Large Recoverable Energy Storage Density and Low Sintering Temperature in Potassiumsodium Niobate-based Ceramics for Multilayer Pulsed Power Capacitors. J. Am. Ceram. Soc. 2017, 100, 1517-1526.

(43) Yang, Z.; Du, H.; Qu, S.; Hou, Y.; Ma, H.; Wang, J.; Wang, J.; Wei, X.; Xu, Z. Significantly Enhanced Recoverable Energy Storage Density in Potassium-Sodium Niobate-based Lead Free Ceramics. J. Mater. Chem. A. 2016, 4, 13778-13785.

(44) Qu, B.; Du, H.; Yang, Z.; Liu, Q.; Liu, T. Enhanced Dielectric Breakdown Strength and Energy Storage Density in Lead-free Relaxor Ferroelectric Ceramics Prepared using Transition Liquid Phase Sintering. RSC Adv. 2016, 6, 34381-34389.

(45) Tian, Y.; Jin, L.; Zhang, H.; Xu, Z.; Wei, X.; Politova, E. D.; Stefanovich, S. Y.; Tarakina, N. V.; Abrahams, I.; Yan, H. High Energy 
Density in Silver Niobate Ceramics. J. Mater. Chem. A. 2016, 4, 17279-17287.

(46) Tian, Y.; Jin, L.; Hu, Q.; Yu, K.; Zhuang, Y.; Viola, G.; Abrahams, I.; Xu, Z.; Wei, X.; Yan, H. Phase Transitions in Tantalummodified Silver Niobate Ceramics for High Power Energy Storage. J. Mater. Chem. A. 2019, 7, 834-842.

(47) Peddigari, M.; Palneedi, H.; Hwang, G.-T.; Ryu, J. Linear and Nonlinear Dielectric Ceramics for High-Power Energy Storage Capacitor Applications. J. Korean Ceram. Soc. 2019, 56, 1-23.

(48) Wu, L.; Wang, X.; Li, L. Lead-free $\mathrm{BaTiO}_{3}-\mathrm{Bi}\left(\mathrm{Zn}_{2 / 3} \mathrm{Nb}_{1 / 3}\right) \mathrm{O}_{3}$ Weakly Coupled Relaxor Ferroelectric Materials for Energy Storage. RSC Adv. 2016, 6, 14273-14282.

(49) Levin, I.; Laws, W. J.; Wang, D.; Reaney, I. M. Designing Pseudocubic Perovskites with Enhanced Nanoscale Polarization. Appl. Phys. Lett. 2017, 111, 212902.

(50) Wang, T.; Jin, L.; Li, C.; Hu, Q.; Wei, X. Relaxor Ferroelectric $\mathrm{BaTiO}_{3}-\mathrm{Bi}\left(\mathrm{Mg}_{2 / 3} \mathrm{Nb}_{1 / 3}\right) \mathrm{O}_{3}$ Ceramics for Energy Storage Application. J. Am. Ceram. Soc. 2015, 98, 559-566.

(51) Zheng, D.; Zuo, R.; Zhang, D.; Li, Y. Novel $\mathrm{BiFeO}_{3}-\mathrm{BaTiO}_{3}-$ $\mathrm{Ba}\left(\mathrm{Mg}_{1 / 3} \mathrm{Nb}_{2 / 3}\right) \mathrm{O}_{3}$ Lead-Free Relaxor Ferroelectric Ceramics for Energy-Storage Capacitors. J. Am. Ceram. Soc. 2015, 98, 2692-2695.

(52) Yang, Z.; Gao, F.; Du, H.; Jin, L.; Yan, L.; Hu, Q.; Yu, Y.; Qu, S.; Wei, X.; Xu, Z.; Wang, Y.-J. Grain Size Engineered Lead-free Ceramics with Both Large Energy Storage Density and Ultrahigh Mechanical Properties. Nano Energy 2019, 58, 768-777.

(53) Lu, Z.; Zhang, H.; Lei, W.; Sinclair, D. C.; Reaney, I. M. HighFigure-of-Merit Thermoelectric La-Doped A-Site-Deficient SrTiO3 Ceramics. Chem. Mater. 2016, 28, 925-935.

(54) Akin, I.; Li, M.; Lu, Z.; Sinclair, D. C. Oxygen-loss in A-site deficient $\mathrm{Sr}_{0.85} \mathrm{La}_{0.10} \mathrm{TiO}_{3}$ perovskite. RSC Adv. 2014, 4, 3254932554 .

(55) Sinclair, D. C.; Morrison, F. D.; Beales, T. P.; Smith, I.; Beales, P. Structure and Electrical Properties of Oxygen-deficient Hexagonal $\mathrm{BaTiO}_{3}$. J. Mater. Chem. 1999, 9, 1327-1331.

(56) Sun, C.; Wang, X.; Li, L. Low Sintering of X7R Ceramics based on Barium Titanate with $\mathrm{SiO}_{2}-\mathrm{B}_{2} \mathrm{O}_{3}-\mathrm{Li}_{2} \mathrm{O}$ Sintering Additives in Reducing Atmosphere. Ceram. Int. 2012, 38, S49-S52.

(57) Liu, K.; Zhang, Y.; Marwat, M. A.; Wang, G.; Wang, D.; Ma, W.; Wei, T.; li, M.; Xu, J.; Yang, H.; Kongparakul, S.; Samart, C.; Zang, J.; Fan, P.; Zhang, H. Large Electrostrain in Low-temperature Sintered NBT-BT-0.025FN Incipient Piezoceramics. J. Am. Ceram. Soc. 2020, 103, 3739-3747.

(58) Iqbal, Y.; Jamal, A.; Ullah, R.; Khan, M. N.; Ubic, R. Effect of Fluxing Additive on Sintering Temperature, Microstructure and Properties of $\mathrm{BaTiO}_{3}$. Bull. Mater. Sci. 2012, 35, 387-394.

(59) Li, L.; Li, M.; Reaney, I. M.; Sinclair, D. C. Mixed Ionicelectronic Conduction in $\mathrm{K}_{1 / 2} \mathrm{Bi}_{1 / 2} \mathrm{TiO}_{3}$. J. Mater. Chem. C 2017, 5, 6300-6310.

(60) Li, L.; Li, M.; Sinclair, D. C. The Influence of Excess $\mathrm{K}_{2} \mathrm{O}$ on the Electrical Properties of $(\mathrm{K}, \mathrm{Na}) 1 / 2 \mathrm{Bil} / 2 \mathrm{TiO} 3$ Ceramics. Appl. Phys. Lett. 2018, 112, 182907.

(61) Li, L.; Li, M.; Zhang, H.; Reaney, I. M.; Sinclair, D. C. Controlling Mixed Conductivity in $\mathrm{Na}_{1 / 2} \mathrm{Bi}_{1 / 2} \mathrm{TiO}_{3}$ using A-site Nonstoichiometry and Nb-donor Doping. J. Mater. Chem. C 2016, 4, 5779-5786.

(62) Aksel, E.; Jones, J. L. Advances in Lead-Free Piezoelectric Materials for Sensors and Actuators. Sensors 2010, 10, 1935-1954.

(63) Muhammad, R.; Iqbal, Y.; Reaney, I. M. $\mathrm{BaTiO}_{3}-\mathrm{Bi}-$ $\left(\mathrm{Mg}_{2 / 3} \mathrm{Nb}_{1 / 3}\right) \mathrm{O}_{3}$ Ceramics for High-Temperature Capacitor Applications. J. Am. Ceram. Soc. 2016, 99, 2089-2095.

(64) Cai, Z.; Wang, H.; Zhao, P.; Chen, L.; Zhu, C.; Hui, K.; Li, L.; Wang, X. Significantly Enhanced Dielectric Breakdown Strength and Energy Density of Multilayer Ceramic Capacitors with High Efficiency by Electrodes Structure Design. Appl. Phys. Lett. 2019, $115,023901$.

(65) Lin, C. C.; Wei, W. C. J.; Su, C. Y.; Hsueh, C. H. Oxidation of $\mathrm{Ni}$ electrode in $\mathrm{BaTiO}_{3}$ based multilayer ceramic capacitor (MLCC). J. Alloys Compd. 2009, 485, 653-659.
(66) Wang, S.-H.; Chai, Y.-L.; Lee, W.-H. A Novel Approach to Sintering $(\mathrm{Ba}, \mathrm{Ca})(\mathrm{Ti}, \mathrm{Zr}) \mathrm{O}_{3}$ Multilayer Ceramic Capacitors with $\mathrm{Ni}$ Electrodes. J. Eur. Ceram. Soc. 2012, 32, 1711-1723.

(67) Zhou, D.; Wang, H.; Yao, X.; Pang, L.-X. Microwave Dielectric Properties of Low Temperature Firing $\mathrm{Bi}_{2} \mathrm{Mo}_{2} \mathrm{O}_{9}$ Ceramic. J. Am. Ceram. Soc. 2008, 91, 3419-3422.

\section{NOTE ADDED AFTER ASAP PUBLICATION}

This paper was published on the Web on September 21, 2020. Reference 47 was removed from the paper, and the subsequent references renumbered. The corrected version was reposted on September 21, 2020. 